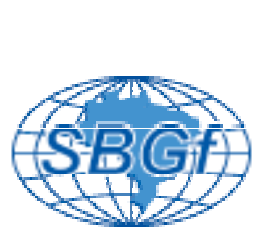

\title{
Comparação entre mapas de isorresistividades elétricas aparentes do solo superficial de Manaus, a partir de séries de dados completos e estatísticos
}

Nilton de Souza Campelo ${ }^{1}$, José Tadeu Alkmin ${ }^{2}$, Fernando César Rodrigues Souza ${ }^{2}$, Aurélio Calheiros de Mello Jr. ${ }^{2}$, Lucas Carvalho Cordeiro ${ }^{2}$, Diógenes dos Santos Paz $\mathrm{Jr}^{2}{ }^{2}$, Aroldo Figueiredo Aragão ${ }^{1}$, Elaine Carvalho da Paz ${ }^{1}$ \& João da Silva Carvalho ${ }^{1}$

${ }_{1}$ - Núcleo de Tecnologia de Materiais; ${ }^{2}$ - Núcleo de Eficiência Energética. Universidade Federal do Amazonas, Av. Gen. Rodrigo Otávio Jordão, 3000 - Coroado - CEP 69.077-000, Manaus, AM. Tel./Fax (92) 644-2194. ccampelo@ufam.edu.br

Copyright 2004, SBGf - Sociedade Brasileira de Geofísica

Este texto foi preparado para a apresentação no I Simpósio de Geofísica da Sociedade Brasileira de Geofísica, São Paulo, 26-28 de setembro de 2004. Seu conteúdo foi revisado pela Comissão Tecno-científica do I SR-SBGf mas não necessariamente representa a opinião da SBGf ou de seus associados. E proibida reprodução total ou parcial deste material para propósitos comerciais sem prévia autorização da SBGf.

\section{Resumo}

Na cidade de Manaus, AM, realizaram-se 138 sondagens elétricas verticais (SEVs) no seu perímetro urbano, empregando-se o método de Schlumberger, com aberturas de malha de eletrodos variando de $1 \mathrm{~m}$ a 300 $\mathrm{m}$. Com os dados coletados, produziram-se mapas de isolinhas de resistividades elétricas aparentes do solo superficial, correspondentes às aberturas de malhas de 1 $\mathrm{m}$ a $5 \mathrm{~m}$. Dez métodos de interpolação de dados foram utilizados, a fim de se obter os mapas de linhas de contorno. Com o emprego de todos os dados, sem exclusão, observou-se que a maioria dos métodos conduz à formação de valores interpolados elevados, em relação aos dados originais medidos, bem como à condução irreal de linhas de contorno em regiões da cidade onde não podem existir dados de resistividade medida. Nestas condições, nenhum dos métodos de interpolação conduziu a resultados realistas. Contudo, quando se empregam conceitos estatísticos às séries de dados coletados, excluindo-se aqueles discrepantes, então há uma nítida melhoria no resultado alcançado nos mapas, fazendo-se com que haja harmonia entre os mapas e as séries de dados.

\section{Introdução}

No perímetro urbano da cidade de Manaus, foram realizadas acima medições de resistividade elétrica aparente do solo, com o fito de se dimensionar conjuntos de aterramento elétrico, para proteção de sistemas de distribuição elétrica. Cada local de medição foi devidamente georreferenciado, sendo posteriormente inserido em um mapa-base da cidade (IMPLAN e CPRM, 1996), procurando-se uniformizar as distribuições espaciais dos pontos medidos. No mapa base, há 15 quadrículas, sendo que duas delas (números 3 e 15) correspondem à porção do rio Negro, e, certamente, não podem apresentar valores de medições de resistividade elétrica do solo. A partir da introdução da localização geográfica e do valor da resistividade do solo, utilizou-se o programa computacional Surfer (Surfer, 2002) para a determinação das curvas de igual valor desta variável física, intentando-se conhecer a sua distribuição quantitativa ao longo da área da zona urbana de Manaus, resultando em facilidade e rapidez de dimensionamento de sistemas de aterramento. O delineamento das curvas e as implicações resultantes serão abordados nos tópicos posteriores.

A área urbana de Manaus possui $11.458,5 \mathrm{~km}^{2}$ (Informe Geo, 2002), localizando-se dentro da Bacia Sedimentar do Amazonas, que compreende uma área de 500.000 $\mathrm{km}^{2}$. A Bacia Sedimentar é intracratônica, apresentando $6.000 \mathrm{~m}$ de preenchimento sedimentar (Cunha et. al., 1994). As unidades litológicas do Cretáceo, Mioceno e Holoceno formam o quadro geológico regional. De acordo com Dino et al. (1999), a Formação Alter do Chão representa a unidade do Cretáceo, compreendendo sedimentos continentais vermelhos (arenitos argilosos, argilitos, quartzos grauvacas, quartzos arenitos e brechas intraformacionais). Os depósitos aluvionares expostos ao longo dos rios e igarapés da região representam a unidade Holocênica. A Formação Alter do Chão apresenta ainda níveis de intensa silicificação, designada por Albuquerque (1922) como Arenito Manaus. Esta Formação predomina na região de Manaus. Os sedimentos foram depositados em ambientes continental aquoso, com significativa contribuição flúvio-lacustrina em processo de imersão não profunda (Caputo et al.; 1972). Tratam-se de depósitos descontínuos, apresentando brusca variação litológica vertical e distribuição espacial irregular, caracterizando variações nos ambientes de deposição dos mesmos. O estudo realizado por Fernandes Filho et. al. (1997), nas unidades informais sobrepostas na cidade de Manaus (Formação Alter do Chão), definiu na região perfis lateríticos do tipo imaturo, observando tanto perfis autóctones (completo), como os alóctones (linhas de pedra). Ademais, a cidade está assentada sobre depósitos Neocretáceos da Formação Alter do Chão, composta por sedimentos incosolidados de arenitos, conglomerados e argilitos de origem fluvial. Tais sedimentos apresentam-se fortemente falhados, cuja característica mais marcante dá-se pelo contraste dos sedimentos arenosos e/ou argilosos de coloração esbranquiçada dessa Formação, com o solo amarelado, realçando tais estruturas. Outra ocorrência marcante é a existência de concreções lateríticas que aparecem constantemente deslocadas.

\section{Métodos de investigação}

Cada local de medição foi escolhido para resultar em distribuições espaciais eqüidistantes, contudo, isto nem sempre foi possível, uma vez que as áreas do centro da cidade e algumas da periferia são urbanizadas por 
calçamento, descartando-se, assim, a possibilidade de se cravar os eletrodos no interior do solo. O método utilizado em todas as medições foi o de Schlumberger, pela sua simplicidade e rapidez. O equipamento empregado foi o resistivímetro Syscal Jr, com potência de $24 \mathrm{~W}$. Ressaltese que, quando possível, foram feitas medições com abertura de malha de até $300 \mathrm{~m}$, a fim de se conhecer a profundidade do nível d'água subterrâneo e do topo rochoso (arenito Manaus). De uma maneira geral, a maior parte das medições ficou compreendida no intervalo de $30 \mathrm{~m}$ a $50 \mathrm{~m}$ de abertura de malha. Cada local de medição foi então catalogado e introduzido no mapa-base da cidade de Manaus (IMPLAN e CPRM, 1996). Devido ao fato de que as dimensões do mapa não permitem sua apresentação neste trabalho, criou-se então um mapa georreferenciado composto de quadrículas cujas coordenadas (utm) são as mesmas do mapa-base original. Os mapas produzidos apresentam variação de profundidade de abertura de malha, de um a cinco metros. A Figura 1 ilustra o mapa, conforme a numeração das quadrículas do mapa-base.

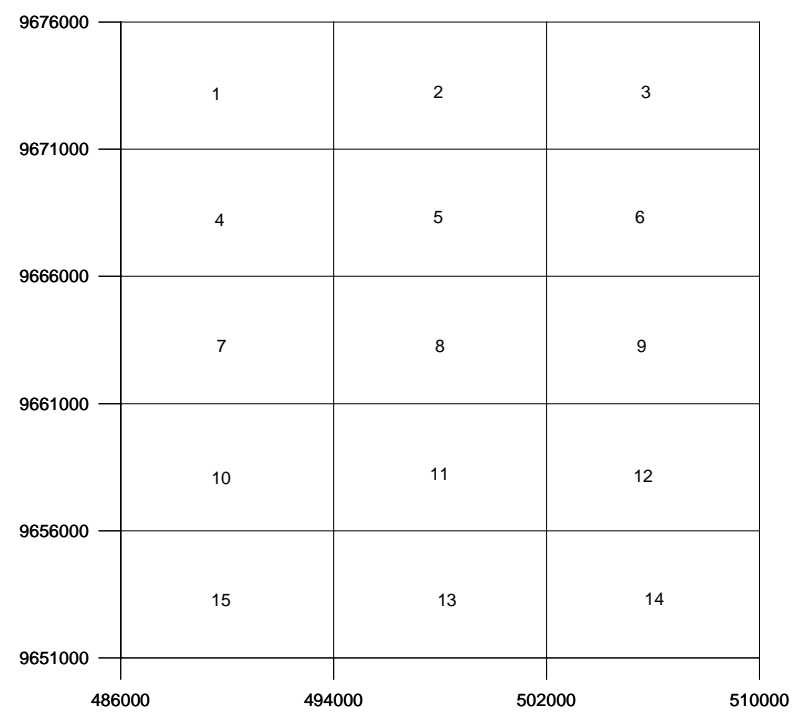

Figura 1 - Mapa-base da cidade de Manaus, dividido em quadriculas.

Deve-se atentar, ademais, para o problema que as quadrículas 3 e 15 não possuem dados de entrada originais, por indicarem porção do rio Negro. É relevante também relatar que as medições nas áreas do centro da cidade ficaram bastante dispersas (quadrículas 1, 2 e 4), pelas razões já relatadas, fruto da completa urbanização de passeios e vias. Como os pontos de medição eram isolados e dado que a área era reduzida para a realização das medições, não se empregou o método de caminhamento nas leituras das resistividades elétricas do solo. As análises das estratificações das camadas de resistividade foram feitas a partir do programa computacional Resix (Resix, 2000). Com os valores definidos das resistividades elétricas, para várias profundidades, foi possível então utilizar os métodos de interpolação, com o fito de se obter a distribuição estatística das resistividades, em função dos seus valores (pesos) e das suas posições (localizações) nos mapas. Ao todo, foram utilizados dez métodos de interpolação, contudo, por brevidade, aqui far-se-á menção apenas a dois deles, a saber: distância inversa à potência e kriging. Os métodos de cálculo procuram fazer as interpolações entre os nós das grades ou malhas, que dependem, por sua vez, dos valores das próprias resistividades e da distância dos pontos aos nós. Cada método pode resultar em representações diferentes dos dados. E vantajoso testar cada método, para determinar qual o que conduz a resultados mais satisfatórios. De uma forma geral, adotou-se uma grade com 2.000 linhas x 2.000 colunas. Em adição, não obstante o fato de que a série completa de dados emprega todos os valores de resistividade, mesmo aqueles excepcionalmente elevados (como o caso de algumas medições de 28.000 $\Omega \mathrm{m})$, procurou-se mostrar nas Figuras apenas os valores interpolados até $5.000 \Omega \mathrm{m}$, com o objetivo de não sobrecarregar o mapa com valores tão dispersos, em relação ao universo representativo da série de dados de entrada original. Ademais, pelo fato de que a série completa sobrelevou demasiadamente os valores interpolados, procedeu-se ao estudo estatístico dos dados, separando-os por classes de valores, em intervalos de $100 \Omega \mathrm{m}$. Assim, eliminaram-se aqueles intervalos que porventura apresentassem freqüência menor que dois. Deste modo, as séries de dados alcançaram até o valor limite de $3.000 \Omega \mathrm{m}$. Este procedimento melhorou sobremaneira a forma e os valores das curvas de isorresistividades elétricas.

\section{Resultados}

As Figuras 2 a 4 mostram as interpolações obtidas a partir do emprego do método da distância inversa à potencia, para as aberturas de malha de um a três metros, utilizando-se a série de dados completa, ou seja, sem exclusão de qualquer valor de resistividade elétrica. Percebe-se as duas áreas em branco, em que o programa Surfer despreza nos cálculos de interpolação, criando duas "barreiras", por onde não devem passar as isolinhas. Ressalve-se, entretanto, o fato de que a área no canto esquerdo inferior extrapola as coordenadas reais fornecidas ao programa, referente à quadrícula número 15, da Figura 1. Claramente, as linhas de contorno tendem a gerar os famosos "olhos-de-boi", principalmente em duas ou três áreas mais densas de dados; ao contrário, dispersa os valores em outras zonas dos mapas. Verifica-se também que este método extrapolou exacerbadamente valores, além da faixa de dados de entrada, o que pode falsear alguns dados particulares. Em linhas gerais, a concentração de faixa de valores de resistividade aparente está situada até 2000 $\Omega \mathrm{m}$, com poucos valores acima deste limite. Observa-se também uma redução gradual dos valores de resistividade elétrica, com o aumento da profundidade, quiçá resultado da maior constância do teor de umidade em regiões mais profundas do subsolo, livres da ação direta das variações sazonais climáticas locais. As Figuras 5 a 7 indicam as interpolações determinadas pelo 
método kriging. Verificou-se, semelhantemente ao método da distância inversa à potência, a formação de "olhos-de-boi", principalmente em torno de duas áreas definidas, em que pese o fato de maior diâmetro que aqueles apresentados neste último método. Além disso, foi averiguado que os valores de resistividade são da mesma ordem de grandeza do método da distância inversa à potencia. Há diminuição dos valores de resistividade aparente com o aumento da profundidade.

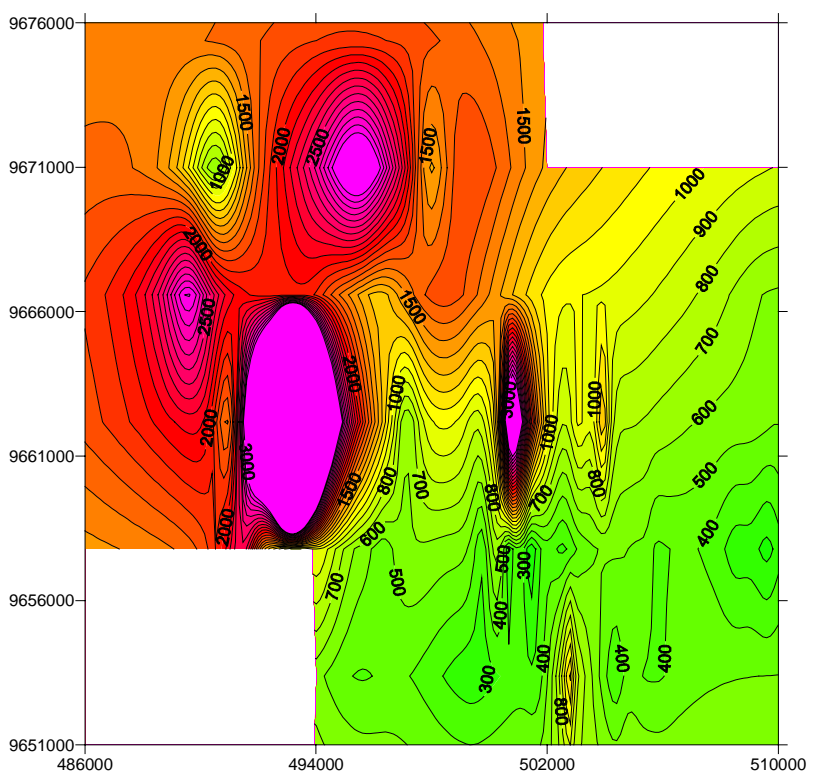

Figura 2 - Método da distância inversa à potencia, para a série completa de dados, com abertura de malha de $1 \mathrm{~m}$.

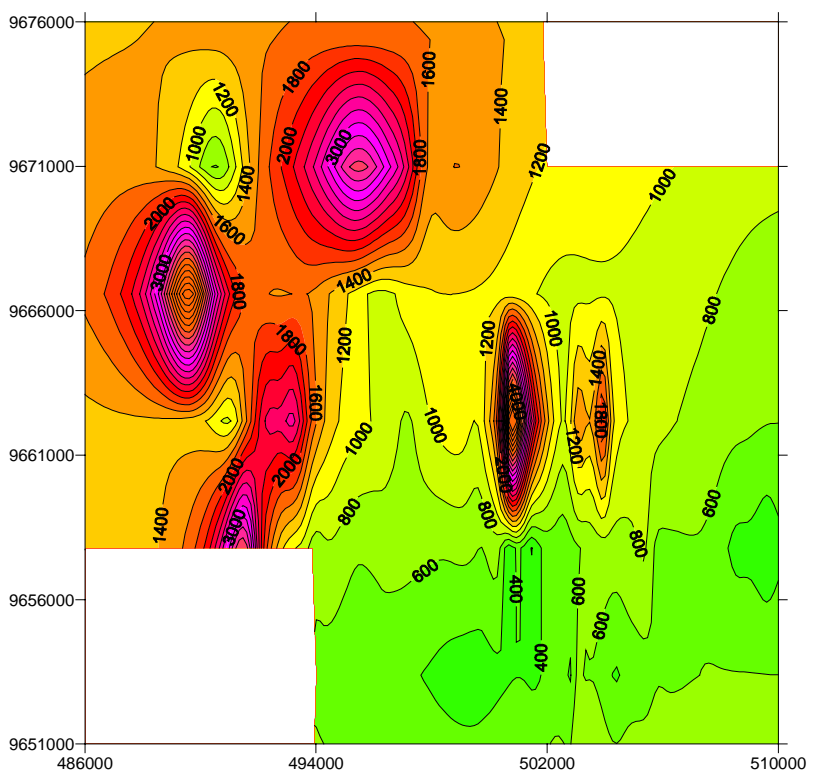

Figura 3 - Método da distância inversa à potencia, para a série completa de dados, com abertura de malha de $2 \mathrm{~m}$.

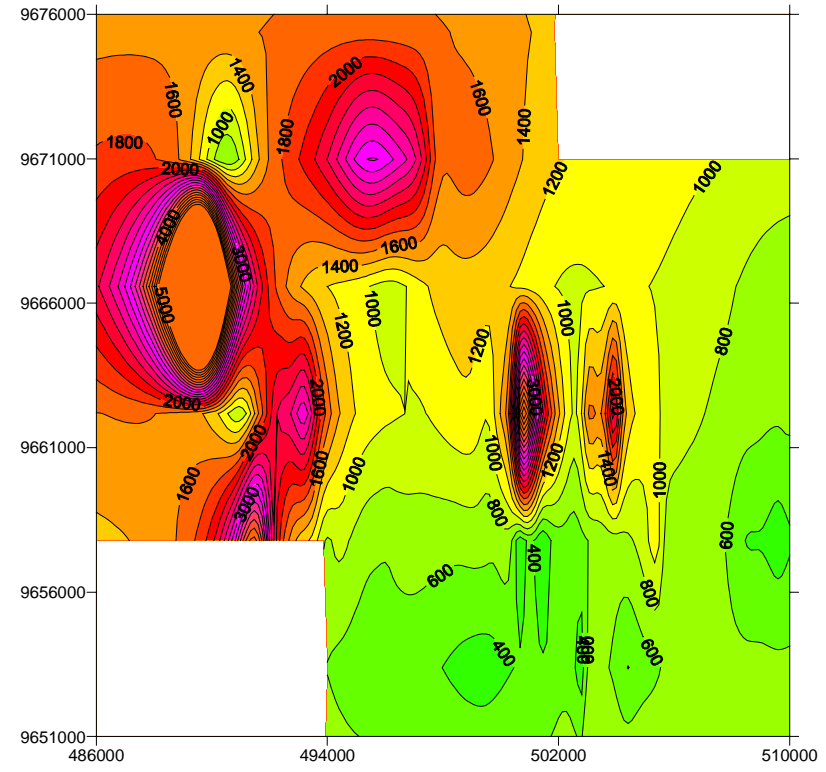

Figura 4 - Método da distância inversa à potencia, para a série completa de dados, com abertura de malha de $3 \mathrm{~m}$.

Notou-se, ainda, a extrapolação de valores, além daqueles realmente medidos, para todas as profundidades estudadas. Pôde-se observar também que há maior área de ocorrência de valores de resistividade maiores que $3000 \Omega \mathrm{m}$. Outro ponto característico comum entre os dois métodos reside na ocorrência de isolinhas nas quadriculas 1, 2 e 4, áreas centrais da cidade, em que praticamente não foram tomadas medidas das resistividades. Desta forma, há uma distribuição de linhas de contorno que apenas medições de campo podem confirmá-las.

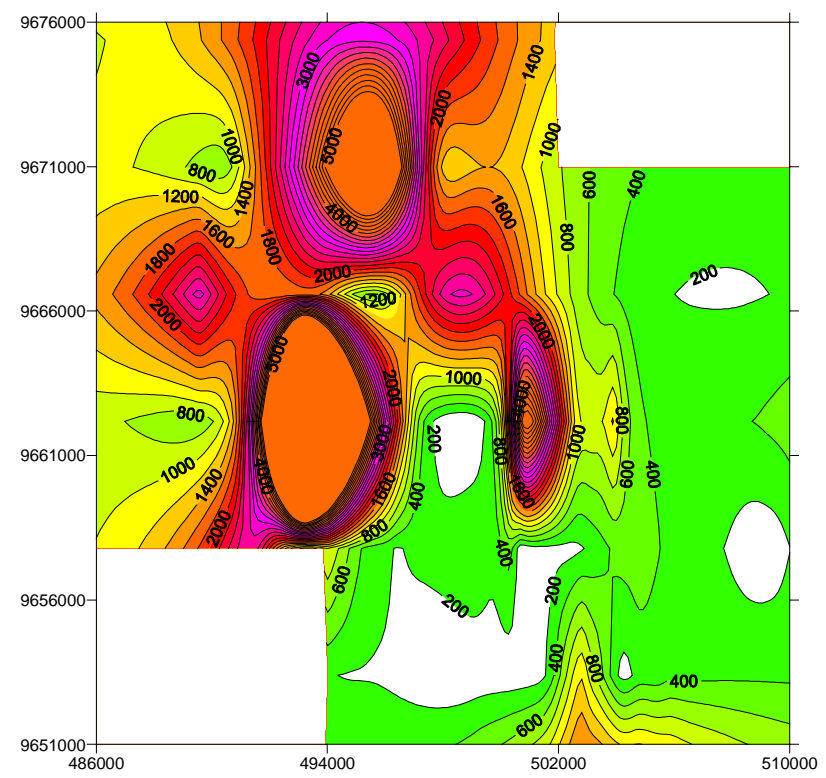

Figura 5 - Método kriging, para a série completa de dados, com abertura de malha de $1 \mathrm{~m}$. 


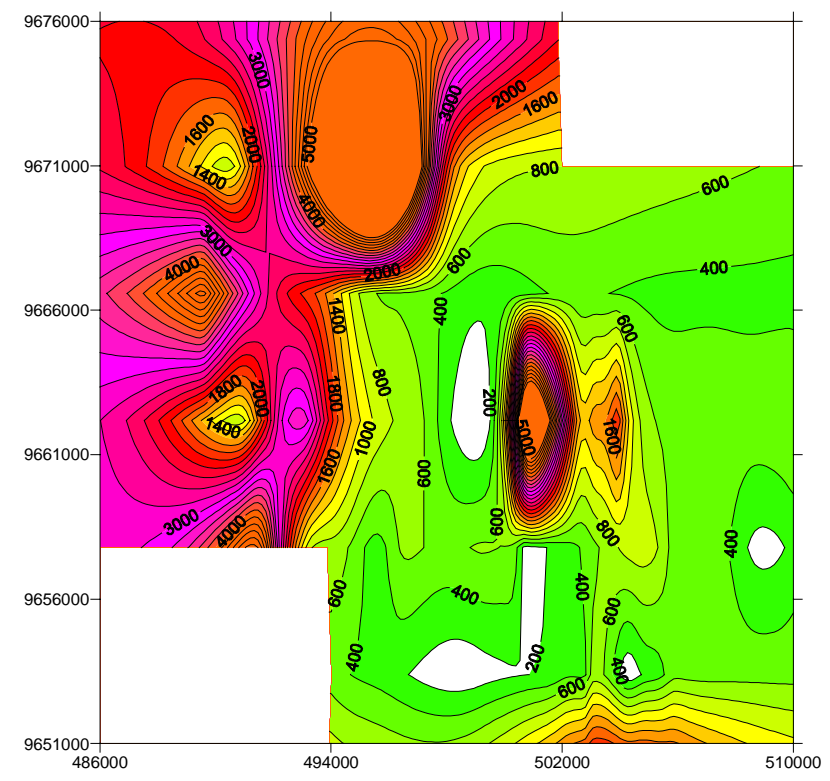

Figura 6 - Método kriging, para a série completa de dados, com abertura de malha de $2 \mathrm{~m}$.

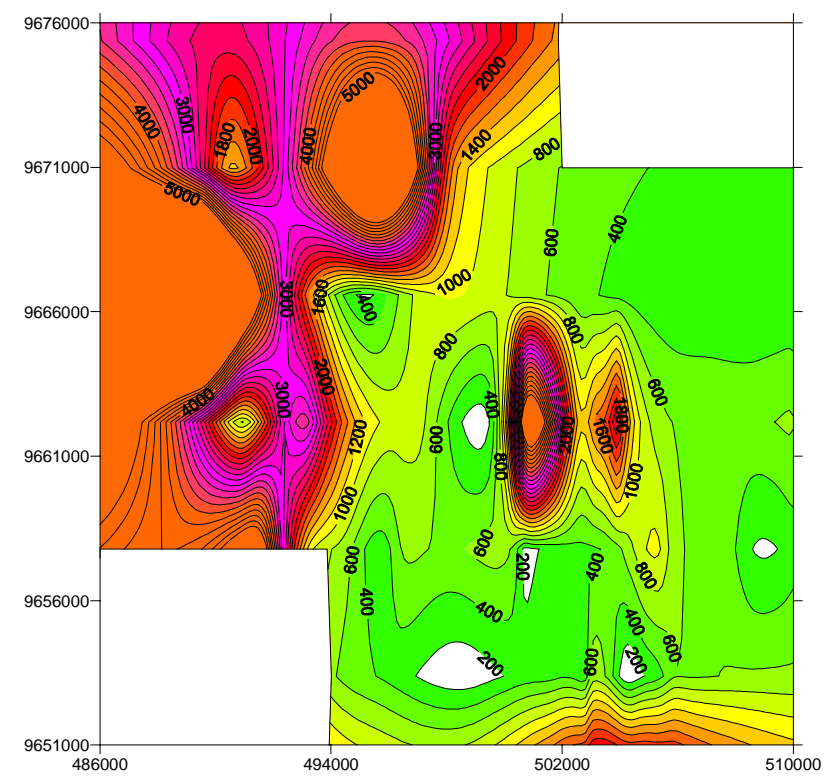

Figura 7 - Método kriging, para a série completa de dados, com abertura de malha de $3 \mathrm{~m}$.

As Figuras 8 a 10 mostram as curvas de contorno obtidas pela interpolação do método distância inversa à potencia, nas condições de exclusão dos valores de resistividade elétrica aparente do solo superiores a $3.000 \Omega \mathrm{m}$, para as aberturas de eletrodos de um a três metros. Já as Figuras 11 a 13 indicam a mesma variação, no entanto, para o método kriging. Observa-se nestas figuras a grande mudança na forma das curvas, doravante muito mais suaves. Ademais, é perfeitamente nítida o aperfeiçoamento nos valores interpolados, mantendo-os mais compatíveis com aqueles efetivamente medidos durante a realização das sondagens elétricas verticais (SEVs). Em adição, verifica-se também que o emprego da série estatística, com exclusão dos valores com baixa freqüência de dados, leva à confecção de mapas que possuem características semelhantes, mesmo variandose a profundidade de medição das resistividades.

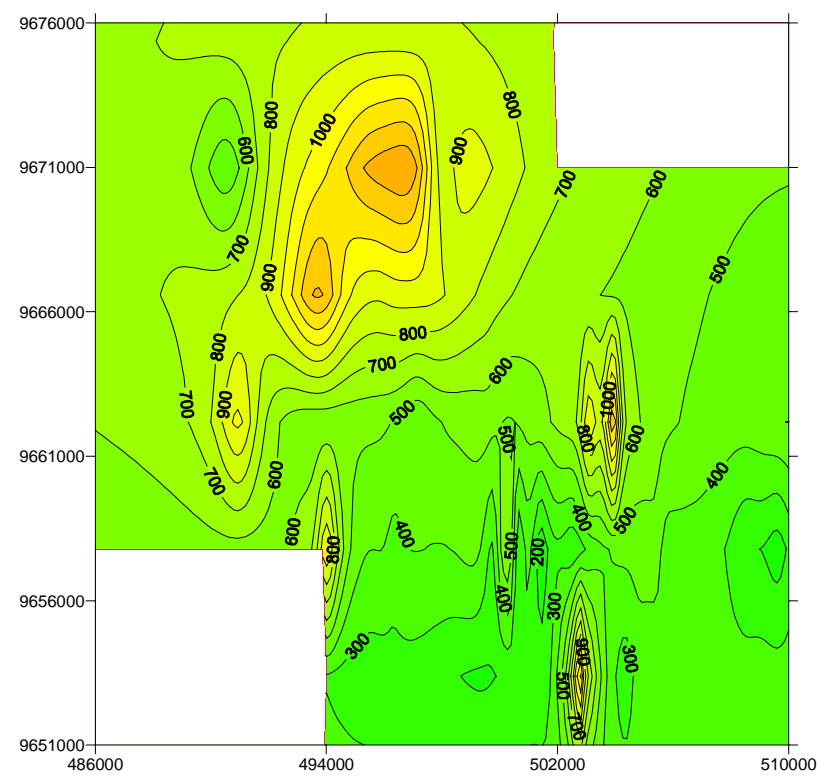

Figura 8 - Método distância inversa à potência, para a série com resistividades inferiores a $3000 \Omega \mathrm{m}$, com abertura de malha de $1 \mathrm{~m}$.

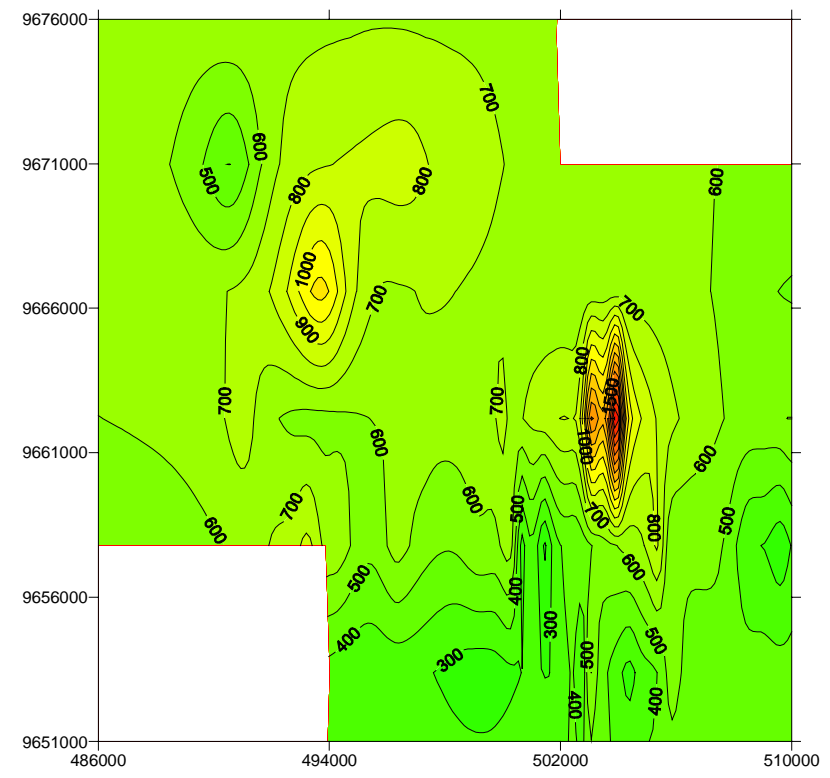

Figura 9 - Método distância inversa à potência, para a série com resistividades inferiores a $3000 \Omega \mathrm{m}$, com abertura de malha de $2 \mathrm{~m}$. 


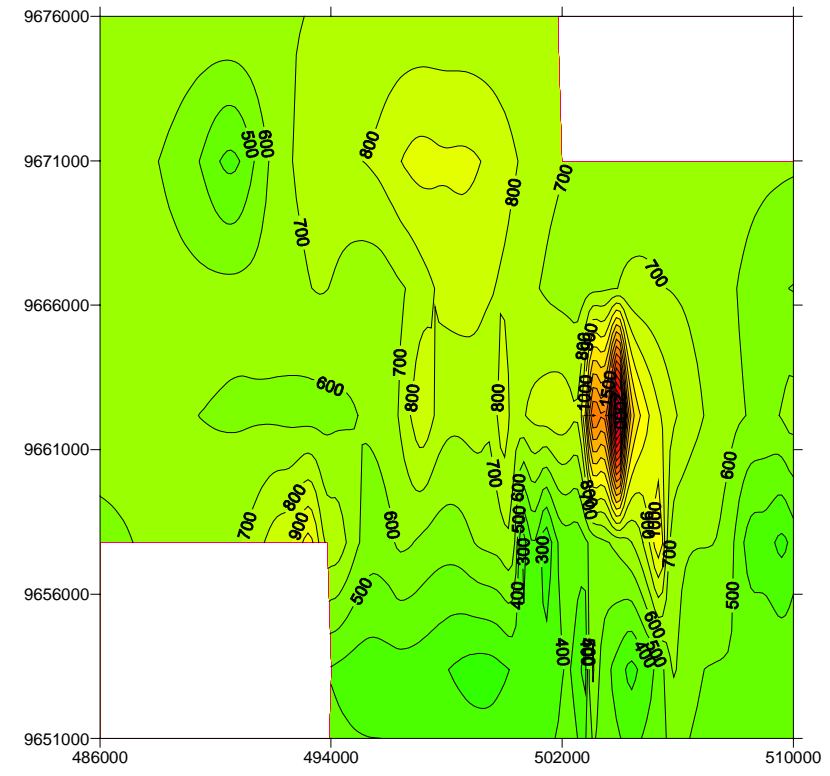

Figura 10 - Método distância inversa à potência, para a série com resistividades inferiores a $3000 \Omega \mathrm{m}$, com abertura de malha de $3 \mathrm{~m}$.

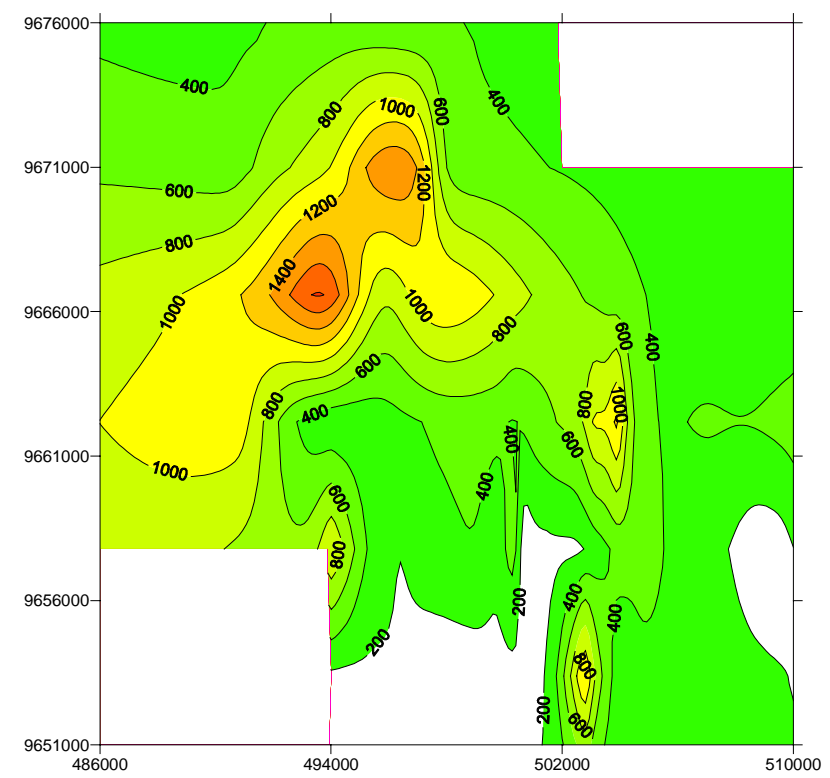

Figura 11 - Método kriging, para a série com resistividades inferiores a $3000 \Omega \mathrm{m}$, com abertura de malha de $1 \mathrm{~m}$.

Mesmo ainda com a persistente formação de "olhos-deboi", nas curvas analisadas, ressalve-se que esta formação está mais dispersa, ao longo da área total de estudo, ao contrário daquela formação encontrada quando da utilização da serei completa de dados.

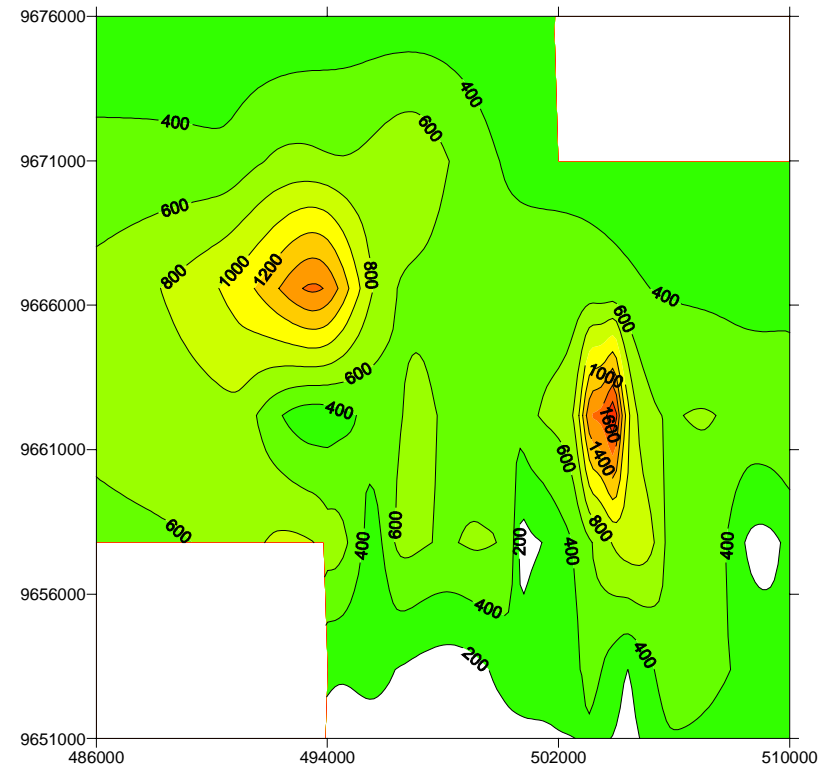

Figura 12 - Método kriging, para a série com resistividades inferiores a $3000 \Omega \mathrm{m}$, com abertura de malha de $2 \mathrm{~m}$.

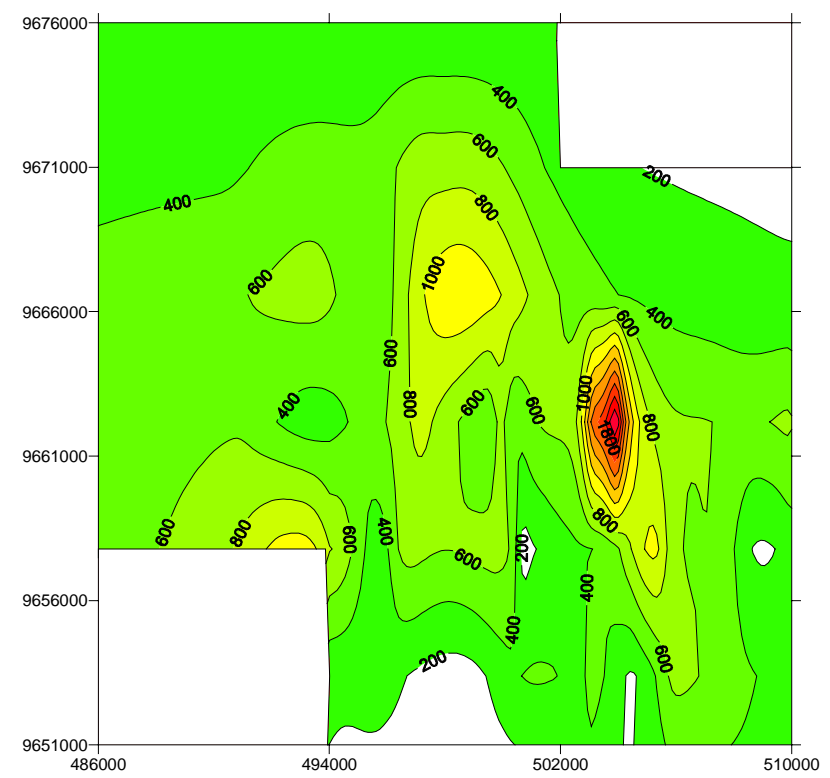

Figura 13 - Método kriging, para a série com resistividades inferiores a $3000 \Omega \mathrm{m}$, com abertura de malha de $3 \mathrm{~m}$.

\section{Discussão e Conclusões (Arial Bold, 9)}

A realização de 138 sondagens elétricas verticais (SEVs) na cidade de Manaus permitiu a elaboração de mapas de isorresistividades elétricas aparentes do solo superficial. Dez métodos de interpolação de valores de resistividade elétrica foram estudados, entretanto, por brevidade, apenas dois métodos foram aqui abordados. Quando se 
utilizou a série completa ou total de valores de resistividade medidos no campo, as curvas resultantes indicaram valores de resistividade bastante sobrelevados, não respeitando os dados originais de entrada. Houve também a formação de "olhos-de-boi" muito concentrados, inclusive em áreas do mapa não efetivamente medidas no campo. Ao contrário, quando se procede à análise estatística dos dados, desprezando-se aqueles valores cujas freqüências foram inferiores a dois, em intervalos de classes de $100 \Omega \mathrm{m}$, então os mapas resultantes tornaram-se muito mais fidedignos aos valores medidos, com suavização nas linhas de contorno e características semelhantes de forma das curvas, mesmo varaindo-se a profundidade de medição. Realizações de SEVs futuramente são imprescindíveis, a fim de se ter maiores dados de entrada para melhor distribuição de pontos medidos, inclusive na zona central da cidade.

\section{Agradecimentos}

Os autores desejam expressar seus agradecimentos à concessionária de energia elétrica Manaus Energia S.A. e à agencia reguladora do setor elétrico ANEEL, patrocinadores do projeto de pesquisa no âmbito P\&D, que resultou na elaboração deste trabalho.

\section{Referências}

Albuquerque, O. R., 1922. Reconhecimento Geológico do Vale do Amazonas. Serv. Geol. Mineral do Brasil, no. 3.

Caputo, M. V., Rodrigues, R. \& Vasconcelos, D.N.N., 1972. Nomenclatura Estratigráfica da Bacia do Amazonas: Histórico e Atualização. Anais $26^{\circ}$ Congresso Brasileiro de Geologia, S.B.G., Belém (PA), vol. 3.

Cunha, P.R.C., Gonzaga, F.G., Coutinho, L.F.C. \& Feijó, F.J., 1994. Bacia do Amazonas. Boletim de Geociências da PETROBRÁS, Rio de Janeiro, vol. 8(1): 47-55.

Dino, R.; Silva, O.B. \& Abrahão, D., 1999. Caracterização palinológica e estratigráfica de estratos cretáceos da Formação Alter do Chão, Bacia do Amazonas. Boletim do 5 Simpósio sobre o Cretáceo do Brasil, p. 557-565.

Fernandes Filho, L.A, Costa, M.L. \& Costa, J.B.S., 1997. Registros neotectônicos nos lateritos de Manaus - AM. Geociências, São Paulo, vol. 16(1).

IMPLAN \& CPRM, 1996. Base cartográfica da área urbana de Manaus. Instituto Municipal de Planejamento Urbano e Informática/ Companhia de Pesquisa de Recursos Minerais. Manaus, AM (em CD-ROM).

Informe Geo, 2002. Projeto Geo Cidades. Relatório Urbano Ambiental Integrado: Manaus, AM. Consórcio IBAM/ISER/REDEH. Rio de Janeiro.
Resix, 2000. User's manual. RESIX 2DI v4, Interpex Ltd., Golden, Colorado, USA.

Surfer, 2002. User's guide. SURFER 8, Golden Software, Inc., Golden, Colorado, USA. 